\title{
A View from the Watershed Revisited
}

\section{Foreword}

This is a very Special Issue of the journal Hydrology and Earth System Sciences (HESS) dedicated to the editorial pen of Jim McCulloch, its founding Managing Editor; it also commemorates the contribution to hydrology as a science of Jim and his staff of the UK Institute of Hydrology. The title HESS is an accurate reflection of the mission of the Institute and of this journal to consolidate the transformation of hydrology over the past five decades from a compendium of unplanned measurements and practical manipulations to systematic measurements and procedures based on scientific principles. This has advanced the acceptance of hydrology as a branch of science capable of offering key solutions to important social problems. It is appropriate that the hydrological community should recognise the considerable contribution of Jim McCulloch to this process throughout his career, as an experimental physicist, mathematician and statistician researching in upland catchment areas in East Africa, to founding Director of the Natural Environment Research Council's Institute of Hydrology at Wallingford and ultimately as Managing Editor of internationally acclaimed scientific journals, initially the Journal of Hydrology and later Hydrology and Earth System Sciences. It is to be hoped that his record and the papers in this Special Issue will encourage the younger generation of hydrologists to follow his example.

The present volume and its dedication provides the European Geosciences Union, formerly the European Geophysical Society, with the opportunity to say "thank you" to Jim for his continuing enthusiasm and service to geophysics and hydrology. His friends and colleagues, who have contributed to this volume, as well as to the presentations at the McCulloch Symposium "A View from the Watershed Revisited" at the 2006 General Assembly of the European Geosciences Union, also celebrate Jim as a scientist, research institute director and educator of upcoming researchers. 